\title{
KAP study about biomedical waste management practices among dental practitioners in urban area of Andhra Pradesh
}

\author{
Krishnaveni Marella \\ PG Student, G Pulla Reddy Dental College and Hospital, Kurnool, Andhra Pradesh, India \\ *Corresponding Author: \\ Email: krishnavenimds@gmail.com
}

\begin{abstract}
Introduction: Bio Medical Waste (BMW) management is an integral part of any health care system. Proper handling, storage, transportation and safe disposal will prevent the chances of nosocomial infections not only among healthcare personnel but also in patients and their relatives visiting the centre.

Objective: To assess the knowledge, attitude and practices about BMW handling among dental practitioners in an urban area of Andhra Pradesh.

Materials and Method: A hospital based cross sectional study was conducted in Kurnool urban area from September 2017 to January 2018. A total of 360 dental practitioners were present in the study area, out of which 320 agreed and gave consent for participation in the study. A pre validated questionnaire was used for the study. Details regarding sociodemographic factors, and on knowledge attitude and practices about biomedical waste management practice were incorporated.

Results: As per the knowledge about the biomedical waste management, 43.4\% had excellent knowledge, 33.8\% good, $19.4 \%$ moderate knowledge regarding the BMW management.

Conclusion: Continuing training programs which emphasize on BMW management practices would assist in improving the present situation of safe handling and disposal of health care waste.
\end{abstract}

Keywords: Biomedical waste, Knowledge, Attitude, Practice.

\section{Introduction}

Bio medical waste management is an integral part of any health care system. Proper handling, storage, transportation and safe disposal will prevent the chances of nosocomial infections not only among healthcare personnel but also to patients and their relatives visiting the centre. Poor management practices result in disaster of placing the public, patients, healthcare personnel and environment at risk. ${ }^{1}$

Proper health care waste management (HCWM) will facilitate the safety of health care personnel and the communities in addition to hospital hygiene. Biomedical Waste Management rules mandatorily makes the health care establishments to dispose their waste proceeded by segregation and disinfection in an environment friendly manner. ${ }^{2}$

Although there is increased level of awareness about the threats posed by the BMW and its suitable handling among health care personnel globally, there seems to be sparse level of awareness in India. ${ }^{3}$ As there was no previous study conducted among dental practitioners in urban area of Kurnool District of Andhra Pradesh, this study was conducted to assess the Knowledge, Attitude and Practices about BMW handling among dental practitioners in an urban area of Andhra Pradesh.

\section{Materials and Method}

A hospital based cross sectional study was conducted in Kurnool urban area from September 2017 to January 2018. Approval from the instititutonal ethical committee was taken for the study. A total of
360 dental practitioners were present in the study area, out of which 320 agreed to participate in the study after explaining about purpose of the study.

A prevalidated questionnaire desgined by Kavita $\mathrm{M}^{1}$ was used in the study. It consisted of details regarding sociodemographic factors, ten close ended questions for assessing the knowledge on BMW management with the correct and incorrect responses. The correct response was given score of one and these were transformed into percentages. A score of less than $25 \%$ was considered as having poor knowledge, $25 \%$ to $50 \%$ as moderate knowledge, $50 \%$ to $75 \%$ as good and more than $75 \%$ as excellent knowledge. The third part of the questionnaire had 10 questions to assess attitude towards health care waste management. The responses were recorded on a 5 point Likert Scale ranging from strongly agree to strongly disagree and transferred to percentages in order to assess the attitude. The last part of the questionnaire had 10 close ended questions with regard to practices with options as yes or no. The collected data was analyzed by SPSS version 22 .

\section{Results}

A total of 320 dental practitioners responded to the questionnaire. More than two third of the participants were females, $84.7 \%$ had post graduate qualification and $28.7 \%$ had work experience of more than ten years. (Table 1) With respect to knowledge about the biomedical waste management $43.4 \%$ had excellent knowledge, $33.8 \%$ good, $19.4 \%$ moderate and $3.4 \%$ of the participants had poor knowledge regarding the BMW management (Fig. 1). 
Of the total subjects $281(87.9 \%)$ responded that disinfection of biomedical waste will reduce chances of hazardous infection and $102(32.1 \%)$ disagreed that waste segregation at the source will increase the risk of injury to the waste handlers. Table 2 depicts the distribution of study participants according to correct attitude response towards BMW management.

Table 3 shows the practices with regard to biomedical waste management. Only $53.4 \%$ respondents used to segregate the BMW into different categories at the source of origin. 134(41.9\%) of the subjects collected waste sharps in puncture proof containers.

\section{Discussion}

The essential components of hospital infection control programme are proper segregation, storage, transportation and safe disposal of BMW. ${ }^{4}$ Any lapse in this process will be hazardous to not only health care personnel but also to communities and environment. ${ }^{5}$ It is the ethical responsibility of dental practitioners to ensure proper implementation of health care waste management policies in their settings.

In our study we found that $43.4 \%$ of the total subjects had excellent knowledge which is similar to findings reported by Kavita $M^{1}$ (2015) where it was around $42.5 \%$, whereas it was higher when compared to study by Sharma et $\mathrm{al}^{3}$ (2013) in which only $30 \%$ had excellent knowledge. Our study reported that $90 \%$ of the subjects agreed that colour code for waste segregation is a must.Sanjeev et $\mathrm{al}^{6}(2014)$ reported it to be $96.6 \%$, Chudasama $^{7}$ (2013) as $96.5 \%$ but it was more when compared to study by Mathur et $\mathrm{al}^{8}$ (2011) wherein $81.3 \%$ of the participants used different colour coded bags for waste disposal.

Thirty three percent of the subjects reported that they treat waste sharps before disposing and 134(41.9\%) used to collect the waste sharps in puncture proof containers. This is in contrast to findings by Mathur et $\mathrm{al}^{8}$ (2011), Chudasama et $\mathrm{al}^{7}$ (2013) and Bansal et $\mathrm{al}^{9}$ (2013) where 65.3\%, 63.1\% and 58\% used to collect waste sharp in puncture proof containers respectively. But it was low in studies done by Charania ${ }^{10}$ (2011) and Osamong et al ${ }^{11}$ (2005). Utmost care is requires to dispose waste sharps, if not, it will be a health hazard.

Only $5.6 \%$ of the participants record and report the accidents/injuries. This can be attributed to the fact that majority of the doctors lack awareness about a formal injury reporting system and priority must be given to establish it in all the health care facilities.

Table 1: Distribution of basic sociodemographic characteristics of the study participants

\begin{tabular}{|l|c|}
\hline Gender & $103(32.1)$ \\
Male & $217(67.8)$ \\
\hline Female & \\
\hline Qualification & $49(15.3)$ \\
B.D.S & $271(84.7)$ \\
\hline M.D.S & \\
\hline Work experience & \\
0-5years & $167(52.2)$ \\
6-10 years & $61(19.1)$ \\
\hline 10 years & $92(28.7)$ \\
\hline
\end{tabular}

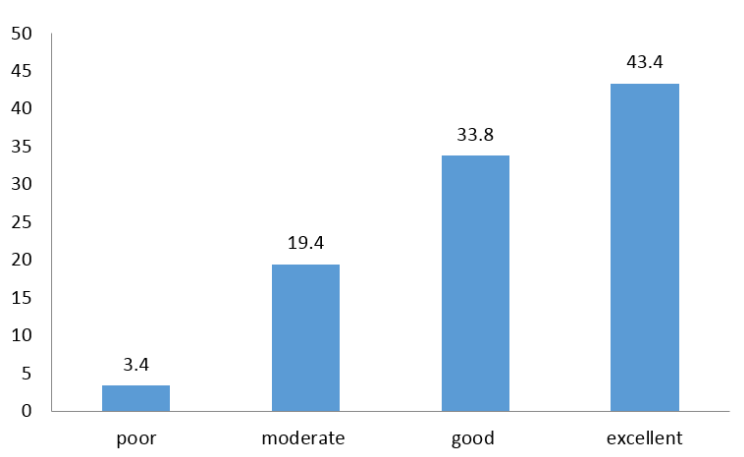

Fig 1: Distribution of participants according to their level of knowledge on Biomedical Waste Management

Table 2: Correct attitude response of participants towards hospital waste management

\begin{tabular}{|l|c|}
\hline \multicolumn{1}{|c|}{ Questions } & Total (\%) \\
\hline $\begin{array}{l}\text { Waste segregation at source increases the risk of injury to waste } \\
\text { handlers }\end{array}$ & $102(32.1)$ \\
\hline Disinfection reduces the chances of infection & $281(87.9)$ \\
\hline Yellow colored plastic bag is used for infectious waste disposal & $2559(81.2)$ \\
\hline For persons involved in waste handling occupational safety is a must & $273(85.4)$ \\
\hline Reporting of needle stick injury is considered as extra burden on work & $197(61.8)$ \\
\hline Colour code bag use for waste segregation is a must & $288(90)$ \\
\hline $\begin{array}{l}\text { Hepatitis B immunization prevents transmission of hospital acquired } \\
\text { infection }\end{array}$ & $62(19.4)$ \\
\hline Post Exposure Prophylaxis should be initiated as early as possible & $279(87.2)$ \\
\hline Health care waste management is the responsibility of government & $145(45.4)$ \\
\hline
\end{tabular}


Table 3: Correct responses for biomedical waste management practices and its management.

\begin{tabular}{|l|c|}
\hline \multicolumn{1}{|c|}{ Biomedical waste management practices } & Total No. (\%) \\
\hline $\begin{array}{l}\text { Do you segregate waste into different categories at } \\
\text { the point of origin }\end{array}$ & $171(53.4)$ \\
\hline $\begin{array}{l}\text { Do you treat sharp waste prior to disposal } \\
\text { Do you dispose infectious waste in yellow colored } \\
\text { plastic bags with biohazard symbol }\end{array}$ & $182(33.4)$ \\
\hline $\begin{array}{l}\text { Do you use heavy duty (puncture proof) plastic container to collect } \\
\text { the waste sharps }\end{array}$ & $134(41.9)$ \\
\hline $\begin{array}{l}\text { Do you use personal protective devices while handling Biomedical } \\
\text { Waste? }\end{array}$ & \\
Apron & $313(97.8)$ \\
Gloves & $315(98.4)$ \\
Mask & $311(97.0)$ \\
\hline Goggles & $9(2.9)$ \\
\hline Do you have the system of recording and reporting injuries/accidents & $18(5.6)$ \\
\hline Do you follow the color coding for segregation of waste & $157(49.1)$ \\
\hline Have you taken vaccination against hepatitis B? & $189(59.1)$ \\
\hline $\begin{array}{l}\text { Following percutaneous exposure do you follow } \\
\text { post exposure prophylaxis }\end{array}$ & $67(20.9)$ \\
\hline
\end{tabular}

\section{Conclusion}

Our study concludes that for successful implementation of BMW management program one of the prerequisite is cooperation and willingness of health care professionals. Safe disposal of BMW will also ensure protection of community and environment .Continuing training programs which emphasize on BMW management practices would assist in improving the present situation of safe handling and disposal of health care waste.

\section{References}

1. Manchanda K, Fotedar S, Dahiya P, Vats A, Sarkar AD, Vats AS. Knowledge, attitude, and practices about biomedical waste management among dental healthcare personnel in dental colleges in Himachal Pradesh: A cross-sectional study. SRM J Res Dent Sci 2015;6:166-9.

2. Umar A, Yaro A. Hospital waste management in Katsina State. Bayero J Pure Appl Sci 2009;2:22-6.

3. Sharma A, Sharma V, Sharma S, Singh P. Awareness of biomedical waste management among health care personnel in Jaipur, India. Oral Health Dent Manag 2013; 12:32-40.

4. Naik R, Sureshchandra B, Hegde S, Damda A, Malik M. Best management practices for hazardous dental waste disposal. Endodontology:108-13.

5. Mohamed Soliman S, Ibrahim Ahmed A. Overview of biomedical waste management in selected Governorates in Egypt: A pilot study. Waste Manag 2007;27:1920-3.

6. Sanjeev R, Kuruvilla S, Subramaniam R, Prashant PS, Gopalakrishnan M. Knowledge, attitude, and practices about biomedical waste management among dental healthcare personnel in dental colleges in Kothamangalam: A cross-sectional study. Health Sci 2014;13:1-12.

7. Chudasama RK, Rangoonwala M, Sheth A, Misra SK, Kadri AM, Patel UV. Biomedical waste management: A study of knowledge, attitude and practice among health care personnel at tertiary care hospital in Rajkot. J Res Med Dent Sci 2013;1:17-22.
8. Bansal M, Vashisth S, Gupta N. Knowledge, awareness and practices of dental care waste management among private dental practitioners in Tricity (Chandigarh, Panchkula and Mohali). J Int Soc Prev Community Dent 2013;3:72-6.

9. Mathur V, Dwivedi S, Hassan MA, Misra RP. Knowledge, attitude, and practices about biomedical waste management amonghealthcare personnel: A crosssectional study. Indian J Community Med 2011;36:143-5.

10. Charania ZK, Ingle NA. Awareness and practice of dental care management among dental practitioners in Chennai city. J Contemp Dent 2011;1:15-21.

11. Osamong LA, Gathece LW, Kisumbi BK, Mutave RJ. Management of dental waste by Practitioners in Nairobi, Kenya. Afr J Oral Health 2005;2:24-9. 